\title{
CONTRIBUIÇÕES DA SOCIOLOGIA FENOMENOLÓGICA DE ALFRED SCHUTZ PARA A COMUNICAÇÃO'
}

\author{
CAMILA GARCIA KIELING CORREIO \\ Pontifícia Universidade Católica do Rio Grande do Sul \\ Porto Alegre, Rlo Grande do Sul, Brasil \\ Email: camila.kieling@gmail.com.
}

1 Artigo publicado, com modificações, nos Anais do XI Congresso de Ciências da Comunicação na Região Sul. 


\title{
CONTRIBUIÇÕES DA SOCIOLOGIA FENOMENOLÓGICA DE ALFRED SCHUTZ PARA A COMUNICAÇÃO
}

Resumo: Este artigo introduz alguns conceitos da sociologia fenomenológica de Alfred Schutz (1899-1959) e relaciona-os com o campo da Comunicação, tomando como base a obra A Teoria da Comunicação de Alfred Schutz, de João Carlos Correia (2005). Essa matriz teórica interessa-se pelas relações entre a consciência humana e a definição da realidade através da produção e da partilha intersubjetiva de significados. Nesse sentido, os meios de comunicação atuam como mediadores, revelando, corroborando ou questionando as relevâncias e tipificações presentes na sociedade.

Palavras-chave: Alfred Schutz; Comunicação; Fenomenologia; Jornalismo

\section{APORTACIONES DE LA SOCIOLOGÍA FENOMENOLÓGICA DE ALFRED SCHUTZ PARA LA COMUNICACIÓN}

Resumen: Este artículo presenta algunos conceptos de la sociología fenomenológica de Alfred Schutz (1899-1959) y los relaciona con el campo de la comunicación, basada en el libro La Teoría de la Comunicación de Alfred Schutz, de João Carlos Correia (2005). Este marco teórico se interesa por la relación entre la conciencia humana y la definición de la realidad a través de la producción y el intercambio de significados intersubjetivos. En este sentido, los medios de comunicación actúan como mediadores, revelando, confirmando o cuestionando las relevancias y las tipificaciones en la sociedad. Palabras clave: Alfred Schutz; Comunicación; Fenomenología; Periodismo

\section{CONTRIBUTIONS OF PHENOMENOLOGICAL SOCIOLOGY OF ALFRED SCHUTZ TO COMMUNICATION}

\begin{abstract}
This paper introduces concepts of the phenomenological sociology of Alfred Schutz (1899-1959) and relates it to the field of communications, based on the book The Communication Theory of Alfred Schutz, of João Carlos Correia (2005). This theoretical framework aims the understanding of the relations between human consciousness and reality, through the production and sharing of intersubjective meanings. In this sense, media acts as mediators, revealing, confirming or questioning the relevances and typifications in society.
\end{abstract}

Keywords: Alfred Schutz; Communication; Phenomenology; Journalism 


\section{ALGUNS DADOS BIOGRÁFICOS}

Alfred Schutz não foi um acadêmico convencional. Somente dedicou-se de forma exclusiva a essa atividade a partir de 1956, aos 57 anos. Viveu grande parte de sua vida como funcionário de um banco em Nova York, e é impossível desvincular esse dado do valor atribuído à vida cotidiana em seus pressupostos teóricos.

O estudioso português João Carlos Correia (2005), autor da única obra em língua portuguesa dedicada à abordagem fenomenológica schutziana da comunicação, informa que o autor nasceu em Viena, na Áustria, em 1899. Judeu, cresceu em um ambiente de homens de negócios bem-sucedidos e teve uma educação sólida, incluindo o estudo de latim, grego e apreciação literária e musical. Aos 17 anos, após concluir os estudos secundários, serviu na Divisão de Artilharia do Exército Austríaco, durante a Primeira Guerra Mundial. A experiência do front teria grande influência em seus textos, ao lado da atuação no mundo dos negócios.

Após o serviço militar, Schutz voltou aos estudos. No nível superior, dedicou-se à Filosofia, Direito, Sociologia e Economia. Logo após, iniciou a carreira nos negócios, com a posição de Secretário Executivo da Associação dos Banqueiros Austríacos. Grande parte da influência em seu pensamento advém da frequência no Círculo de Ludwig von Mises, um dos numerosos círculos vienenses que reuniam intelectuais para promover discussões interdisciplinares. Foi através desses debates que Schutz entrou em contato com as obras de Henri Bergson e de Edmund Husserl, com os quais manteve longa correspondência.

Os movimentos de Hitler na Europa, em especial a anexação da Áustria pela Alemanha, em 13 de março de 1938, influenciam a carreira acadêmica e de negócios de Schutz, que se exilou primeiro em Paris, e depois em Nova York, onde aportou em 1939. Nos Estados Unidos, torna-se cofundador da International Phenomenological Society e funda a revista Philosophy and Phenomenological Research, onde publica diversos textos, mais tarde editados sob o título Collected papers. Participa da organização do Departamento de Filosofia da New School of Social Research e, como já comentamos, apenas em 1956 passa a dedicar-se com exclusividade à vida acadêmica. Infelizmente, essa entrega dura pouco, com o falecimento de Schutz em maio de 1959. Sua mais importante obra, The structures of the life-world, foi finalizada pelo discípulo Thomas Luckmann e publicada postumamente, em dois volumes, datados de 1973 e 1984. 
Assim, a trajetória de Schutz resume-se, nas palavras de Husserl, a "banqueiro de dia e fenomenólogo de noite" (CORREIA, 2005, p. 31). Seu caminho biográfico tem especial significado se coadunado com suas perspectivas teóricas, onde o repertório de conhecimentos adquiridos pelos indivíduos ganha importante significado em suas relações com o mundo da vida:

[...] Este contato com o mundo do trabalho exterior à academia e com as preocupações cotidianas aguçou o seu engenho descritivo e a sua excelente relação com o mundo prático da cotidianidade, tornando ao mesmo tempo seus ensaios extremamente acessíveis e criativos para além de extremamente rigorosos na fundamentação teórica (CORREIA, 2005, p. 31).

A própria forma de produzir de Schutz diz muito sobre sua posição como intelectual: sua obra é majoritariamente constituída por textos curtos, ensaios independentes. Trata-se de uma produção fragmentada, característica que pode ser explicada pelo curto tempo disponível para os estudos, já que o cargo ocupado no banco exigia dedicação integral (WAGNER, 1979). Outro traço distintivo da produção de Schutz diz respeito ao intenso diálogo que ele estabeleceu com outros autores, como Husserl e Bergson, através da troca de correspondências.

\section{A SOCIABILIDADE NA OBRA DE SCHUTZ}

Schutz incorpora o mundo da vida cotidiana na investigação sociológica. Traz como objeto de estudo o âmbito da sociabilidade, ou seja, "o conjunto de relações interpessoais e atitudes pessoais que, ainda que dependam de padrões adquiridos, são pragmaticamente reproduzidas ou modificadas na vida quotidiana" (CORREIA, 2005, p. 12). Nesse sentido, o autor parte da constatação de que a realidade é construída socialmente através do conhecimento, ou seja, das diferentes atribuições de sentido que os seres humanos desenvolvem em determinados contextos.

Berger e Luckmann (1991), autores que partem dos pressupostos teóricos de Schutz para desenvolver sua Sociologia do Conhecimento, na obra A construção social da realidade, definem de forma bastante sintética (mas eficiente) os conceitos de "realidade" e "conhecimento", de forma que, como eles mesmos pretendem no livro, possamos também neste artigo dispensar as aspas nesses termos. A explicação é necessária justamente pelo caráter 
de senso comum que invade os conceitos: o conhecimento e a realidade não podem ser os mesmos para o pesquisador social e o homem comum. A realidade constitui "uma qualidade pertencente a fenômenos que reconhecemos terem um ser independente de nossa própria volição (não podemos desejar que não existam)" e o "conhecimento" é a "certeza de que fenômenos sociais são reais e possuem características específicas" (p. 11).

Em um exemplo bastante prosaico, isso explica porque não procuramos no mapa a localização de nossa casa a cada vez que queremos nos dirigir a ela. Nossa casa é uma realidade, e o conhecimento que temos sobre ela permite que nos desloquemos até lá todos os dias, sem questionamentos.

Tornando a questão mais complexa, o interesse sociológico pela relação entre a realidade e o conhecimento justifica-se pela sua relatividade social: o que é real para um monge tibetano pode não ser real para um homem de negócios americano (BERGER; LUCKMANN, 1991, p. 13). Ou seja: existem agrupamentos de noções de realidade e de conhecimento em contextos sociais específicos, que podem ser analisados sociologicamente.

Fica claro, a partir de Schutz, que a intersubjetividade é um elemento essencial na construção social dos sentidos. Correia (2005) explica que "a comunicação [...] desempenha um papel estruturante nas manifestações concretas de sociabilidade" (p. 15-16). Os meios de comunicação aparecem, então, como mediadores das subjetividades, atuando de forma contundente na construção da realidade, ao iluminar determinadas relevâncias e afirmar ou questionar as tipificações presentes no mundo da vida, como veremos a seguir, com o aprofundamento desses conceitos.

No terreno da sociabilidade, ocorre uma negociação entre os indivíduos através do processo comunicativo, que permite que os sujeitos entrem em contato com os pensamentos uns dos outros, mas não de forma completa. Assim, a comunicação, de forma bastante frequente, também produz estranhezas, plano tão importante quanto o do entendimento na produção de significados, segundo a teoria de Schutz:

A comunicação implica a constituição de universos de significado comuns onde é possível compreender e sermos compreendidos graças a um processo de geração recíproca de expectativas no decurso da qual construímos uma idéia partilhada de realidade (CORREIA, 2005, p. 16). 
Assim como torna possível esses universos de significados comuns e a coesão da noção de realidade no tecido social, veremos que a comunicação também oportuniza o questionamento e o tensionamento do que é tido como comum ou natural na vida cotidiana.

\section{A atitude natural, o mundo da vida e seus significados}

É importante entender o lugar onde ocorre a experiência, dada sua centralidade na formação da consciência. Para Husserl, um dos principais teóricos que embasaram o pensamento de Schutz, esse lugar é o mundo da vida, ou Lebenswelt. Trata-se da vida cotidiana, do modo como percebemos, interpretamos e agimos no mundo em que nos encontramos. É aquilo que está dado e sobre o qual a dúvida está suspensa; o entendimento comum e adequado daquilo que nos cerca (CORREIA, 2005, p. 34).

O método proposto por Husserl, para entender os fenômenos, tem como ponto de partida as experiências do ser humano. Para ele, a consciência humana está sempre ligada a um objeto, material ou não. A construção desses objetos é intencional, e se dá na síntese dos diferentes olhares lançados pelos indivíduos a eles, os quais são posteriormente relembrados de forma generalizada, tipificada (WAGNER, 1979). Assim, o método fenomenológico de Husserl sugere a reflexão sobre a consciência, num procedimento chamado redução fenomenológica - epoché - onde o mundo da vida cotidiana é colocado entre parênteses. Isso significa atingir o momento de consciência anterior ao mundo que sempre foi assim, importando para o pesquisador como se dá a construção dos significados. Desta forma seria possível chegar ao eidos, ou seja, à essência dos fenômenos. Correia (2005) explica o processo da seguinte forma:

É pelo método da redução fenomenológica, suspendendo a crença do investigador na existência factual do mundo externo, que é possível revelar os atos intencionais pelos quais os fenômenos são constituídos na consciência. [...]

Graças à epoché, o sujeito livra-se de seu entrave mais íntimo e secreto, a consideração do mundo como um pré-dado, alcançando absoluta autonomia em relação ao mundo e à consciência que dele possui (p. 35). 
Trata-se, então, de colocar entre parênteses o conhecimento prático do mundo, os pressupostos das ciências e a existência dos outros e de mim mesmo. Assim, no lugar de se regressar às coisas, regressa-se à correlação entre a consciência e as coisas. Em última análise, interessa ao fenomenólogo a construção dos significados.

A análise da atitude natural e do mundo da vida diz respeito à socialidade, ao mundo dos homens que atribuem significado aos objetos e às ações que praticam. No plano científico, essa visão fundamenta uma Ciência Social compreensiva, que tenta superar a relação sujeito-objeto que ocupa a história do pensamento desde Descartes e do mundo quantificado da ciência moderna.

Schutz parte de onde parou Husserl: da análise do plano mundano, debruçando-se em especial sobre a comunicação, a intersubjetividade e a sociabilidade. $O$ fio condutor de seu pensamento é a relação entre a consciência e o mundo; e a forma que vivemos o mundo é através da atitude natural:

O mundo da vida cotidiana significará o mundo intersubjetivo que existia muito antes do nosso nascimento, vivenciado e interpretado por outros, nossos predecessores, como um mundo organizado. Ele se dá agora à nossa experiência e interpretação. Toda interpretação desse mundo se baseia num estoque de experiências anteriores dele, as nossas próprias experiências e aquelas que nos são transmitidas por nossos pais e professores, as quais, na forma de conhecimento à mão, funcionam como um código de referência (SCHUTZ, 1979, p. 72).

Esse conhecimento à mão constitui um repertório e, assim como a redução fenomenológica, a atitude natural consiste em um processo de redução. Trata-se da suspensão da dúvida sobre uma realidade que é preponderante sobre todas as outras:

A certeza de que o mundo existe antes de mim e que vai continuar de eu sair sustenta a história dos meus predecessores, a interação com meus contemporâneos e consociados e os projetos que os afetarão e aos meus sucessores. A atitude natural trabalha com a certeza dos agentes quanto a uma realidade exterior a todas as subjetividades, tomando como dado o mundo existente e suas leis. Só assim os agentes podem reproduzir, rotineiramente, as condições dessa realidade, que é apreendida a partir do conhecimento de receitas e comportamentos, entendidos de um modo que permite assegurar a continuidade da ordem social (CORREIA, 2005, p. 38 ). 
A epoché da atitude natural ocorre no mundo da vida, no cotidiano, onde os interesses são predominantemente do campo da ação, da pragmática. Ou seja: não passamos o tempo todo questionando as nossas ações; grande parte delas está no terreno do evidente, do espontâneo, de forma eminentemente prática. Schutz (1979) divide o mundo social em quatro "submundos", de acordo com a experiência partilhada de tempo e espaço:

- mundo dos consociados (Umwelt): é o mundo em que compartilhamos tempo e espaço com os outros, com a proximidade do face a face, criando, entre pessoas que se reconhecem como semelhantes, um relacionamento de Nós, com orientação-para-o-tu;

- mundo dos contemporâneos (Mitwelt): Trata-se da orientação-para -eles, onde não há uma experimentação direta ou imediata de nossos contemporâneos. Esse mundo usa recursos de tipificação e é caracterizado pelo anonimato;

- mundo dos predecessores (Vorwelt): é o passado, acabado e feito, fixo e determinado;

- mundo dos sucessores (Folgewelt): é futuro, totalmente indeterminável.

Conforme vamos nos afastando do Umwelt, as relações tornam-se cada vez mais distantes, anônimas e inacessíveis à experiência. Por isso, criamos processos de tipificação (grosso modo, generalizações) para caracterizar nossos semelhantes. Em nossa consciência, sintetizamos nossas interpretações das experiências pessoais e alheias para estabelecer relações de familiaridade ou estranheza com o mundo.

Assim, passado, presente e futuro se misturam no mundo da vida. Para Schutz, o corpo é como um marco zero de coordenadas que permitem a orientação dos indivíduos no mundo e que definem os conhecimentos que estão ao seu alcance ou potencialmente ao seu alcance. A estrutura espacial relacionase com a dimensão temporal da consciência: "o mundo ao meu alcance - a face presente da corrente da consciência; o mundo que pode ser recuperado de modo a estar de novo ao meu alcance - a memória; o mundo que pode efetivamente vir a estar ao meu alcance - a expectativa" (CORREIA, 2005, p. 60).

$A$ atitude natural é, portanto, baseada num conhecimento no mundo da vida, organizado pelas experiências partilhadas com contemporâneos e predecessores e na projeção de nossos sucessores. Ao mesmo tempo, adiciona Schutz, a realidade cotidiana é atravessada por outras realidades, províncias de significado, e isso ocorre através da troca de experiências e da 
transcendência dos limites daquilo que julgamos real. Para além daquilo que está prontamente ao nosso alcance, estão os espaços potenciais, possíveis de serem alcançados. As múltiplas realidades relacionam-se com a possibilidade de "transcender a quotidianidade através de símbolos" (SCHUTZ e LUCKMANN apud CORREIA, 2005, p. 46).

Assim, as províncias de significado não são estanques. Da mesma forma que os sujeitos dividem o que lhes parece semelhante, os elementos estrangeiros, marginais, atuam nessas províncias como um questionamento eminente de forma que "[...] cada província de significado outra coisa não é senão um domínio de crenças válidas enquanto os sujeitos as partilharem" (CORREIA, 2005, p. 48). É também no terreno da sociabilidade e da comunicação que ocorre a transformação da vida cotidiana, do que é dado como certo, rotineiro. Na fenomenologia social, o contato intersubjetivo, ou a comunicação, "é pré-requisito para toda a experiência humana imediata no mundo da vida" (p. 50), o que faz com que o entendimento do próprio "eu" dependa da relação com os outros indivíduos.

No caso do discurso, do uso de palavras, a observação genuína do outro só se dá quando é possível relacionar o discurso com uma indicação sobre as experiências subjetivas de quem fala, ou seja, com o que o outro quer dizer. Assim, Schutz, ao complementar a teoria husserliana de intersubjetividade, afirma que só podemos entender as intenções do outro através de dados do cotidiano, e não do que isso representa para essa pessoa subjetivamente em uma esfera transcendental.

Ao adentrar nas formas mais remotas e anônimas de interação subjetiva, Schutz aproxima a sua sociologia fenomenológica da Comunicação Social. Nesse sentido, os conceitos de relevância e tipificação são essenciais ao entendimento do conhecimento comum que está presente no discurso midiático.

\section{Relevância e tipificação: conceitos-chave para a comunicação}

De forma simplificada, as tipificações constituem as generalizações usadas na vida cotidiana como facilitadoras e simplificadoras do pensamento e das ações. São um acervo de conhecimento sedimentado cotidianamente através das experiências e do convívio social e que serve para viver e interpretar esse mundo. Correia (2005) explica: 
Na tipificação, os objetos do mundo social estão constituídos dentro de um marco de familiaridade e de reconhecimento proporcionados por um repertório de conhecimentos disponíveis cuja origem é sobretudo social. É o que habitualmente Schutz designou de acervo de conhecimentos disponíveis (p. 92).

As tipificações partem do pressuposto de que há uma ordem garantida, ou seja, que o mundo existe e faz sentido, podendo ser explicado por esse conjunto de conhecimentos disponíveis. Ao lado da atitude natural, as tipificações consagram a ordem social, numa esfera eminentemente relacionada à prática, e às rotinas. A crença nessa espécie de permanência, o sempre foi assim, é também o que orienta o modo como lidamos com o extraordinário, o inesperado.

Schutz questiona, então, como é possível fazer ciência com base nas construções do senso comum. E é nesse ponto que o autor defende a fundação da tipificação científica, a noção de tipo ideal, com base na vida cotidiana. Os tipos ideais constituem uma síntese científica, uma padronização, uma cristalização que ordena o estudo dos fenômenos sociais. Apoiado em Weber, Schutz situa esse esforço no sentido de um tratamento objetivo de realidades dotadas de significados subjetivos, onde o cientista assume o papel de observador desinteressado, comparável ao processo de aprendizado do estrangeiro, quando chega a uma cidade desconhecida, ou com o veterano de guerra que regressa para casa:

O estranho... torna-se em essência o homem que tem de colocar em questão praticamente tudo aquilo que parece inquestionável para os membros do grupo do qual se aproximou.

Para ele, o padrão cultural do novo grupo não tem a autoridade de um sistema comprovado de receitas, e isso, se por nenhum outro motivo, porque ele não participa da tradição histórica "vivida" através da qual o grupo se formou (SCHUTZ, 1979, p. 87).

Assim, a figura do estranho ou do estrangeiro aparece na obra de Schutz como uma metáfora do comportamento do pesquisador, no momento em que atribui sentido a processos de atribuição de sentido. $O$ autor faz um paralelo entre o fazer científico do sociólogo com a atividade de um cartógrafo que, no lugar de dados matemáticos, usa os relatos dos moradores 
da cidade para desenhar seu mapa (CORREIA, 2005, p. 95-97). O olhar do observador desinteressado torna-se possível através dos tipos ideais, para os quais Schutz define quatro princípios aplicáveis:

1) Relevância: diz que o problema selecionado pelo pesquisador cria, ele mesmo, um esquema de conceitos e tipos a serem utilizados. Ou seja: o problema de pesquisa pede determinada organização teórica;

2) Consistência lógica: refere-se à validade objetiva do objeto de estudo, que deve ser claro e nítido como a lógica formal;

3) Interpretação subjetiva: é o momento hermenêutico, onde o cientista deverá imaginar como construir um modelo de pensamento individual que lhe permita "construir um conhecimento objetivo e verificável de uma estrutura de significado subjetivo" (CORREIA, 2005, p. 98). Aqui, há a indicação de que o pesquisador deverá realizar o exercício de despir-se de sua situação biográfica ou, reconhecendo a impossibilidade de tal tarefa, aplicar o questionamento das tipificações como regra: "o que é tido como sendo da maior relevância num nível passa a ser relativamente irrelevante noutro nível” (p. 98);

4) Adequação: pretende a aproximação entre as construções científicas feitas sobre o objeto de pesquisa e as construções do agir cotidiano. É preciso que o cientista se faça entender pelos seus contemporâneos, ou seja: mesmo que se refira a algo distante no sentido histórico, social, moral ou econômico, deve buscar a compreensão, tematização e explicitação dos contextos da experiência dos atores (CORREIA, 2005, p. 99).

É importante entender que as tipificações estão submetidas socialmente à sua relevância, ou seja, à orientação dos interesses e da atenção dos sujeitos a um determinado assunto. "A relevância diz respeito à atenção seletiva pela qual estabelecemos os problemas a serem solucionados pelo nosso pensamento e os objetivos a serem atingidos pelas nossas ações" (SCHUTZ apud CORREIA, 2005, p. 100). A orientação do olhar dos agentes sociais está relacionada com as tradições, com os costumes e, desta forma, a relevância desempenha diferentes e importantes funções, como: determinar os fatos que devem ser tratados como semelhantes; funcionar como orientação e ajudar a construir um universo discursivo comum; favorecer e facilitar as interações humanas. Mesmo derivando das relações intersubjetivas, a relevância nem sempre é espontânea, podendo também ser imposta ou motivada.

A variabilidade do sistema de relevâncias tem importantes efeitos para a teoria da comunicação, dado que o mundo da vida, como vimos, é um mundo de significados intersubjetivamente partilhados, onde a linguagem atua 
CONTRIBUIÇÕES DA SOCIOLOGIA FENOMENOLÓGICA

DE ALFRED SCHUTZ PARA A COMUNICAÇÃO

como sistema de tipificação:

A comunicação entre os sujeitos se dá no mundo da vida cotidiana e o processo de criação de significados baseia-se na memória das experiências. No cruzamento ou na comunicação entre essas memórias é possível transcender o mundo mais próximo de mim e visitar outras províncias de significado. Mas isso não se dá de forma fácil, clara ou direta. Apesar de constituir um elemento essencial da sociabilidade, "Schutz não deixou nunca de ter em conta que a comunicação plenamente bem sucedida é impossível e que há sempre uma margem da vida privada do outro que me é inacessível e transcende as minhas experiências possíveis" (CORREIA, 2005, p. 106).

Os processos intersubjetivos, incluindo aí a Comunicação, para Schutz, desempenham um duplo papel, ou seja: promovem a coesão social, ao dar sentido ao mundo da vida cotidiana e, ao mesmo tempo, proporcionam a transcendência das experiências, mesmo em face de sua imponderabilidade, falência, ou incompletude. A transcendência pode se dar de formas mais simples, como na transposição de fronteiras espaciais (uma viagem, por exemplo), ou mais complexas, como o sonho, o êxtase, a experiência religiosa ou a proximidade da morte. É importante ressaltar a diferença conceitual que Schutz consolida entre a intersubjetividade e a comunicação: "[...] a intersubjetividade é prioritária em relação à comunicação" (CORREIA, 2005, p. 110). De modo que nem toda ação dotada de significado é comunicativa, pois a comunicação é marcada pela intencionalidade. A ação comunicativa espera, mais do que ser compreendida, produzir um determinado efeito no receptor.

Assim, a palavra tem uma face fantasmagórica, pois refere e torna possível o intercâmbio das experiência interiores, mas as capta em si, de forma pura. No terreno da comunicação, essa característica da linguagem está relacionada com a dificuldade de que o receptor entenda exatamente aquilo que o emissor quis dizer, pois:

O que se comparte é um significado linguístico e não uma experiência, de tal modo que se origina uma possível discrepância entre o sentido que lhe dá o que a pronuncia e o sentido alcançado por aquele que interpreta. A linguagem surge deste modo como um conjunto de tipificações socialmente aceites, de acordo com um sistema de relevância (CORREIA, 2005, p. 114-115). 
As próprias palavras constituem uma pré-interpretação do mundo que pretendem referir: "A linguagem constrói o mundo na sua tipicalidade sendo por isso o meio tipificador por excelência através do qual se transmite o conhecimento socialmente relevante" (CORREIA, 2005, p. 115).

Os sistemas de relevâncias e tipificações, num dado momento histórico, são uma herança social que desempenha funções importantes, como: determinar os fatos e as situações que devem ser tratados como homogêneos; transformar as ações individuais em papéis sociais típicos (é aquilo que se espera de um homem de negócios ou de um monge); funcionar como um código de interpretação e orientação dos indivíduos em um determinado grupo, assim como um universo de discurso comum, para fins de compreensão mútua; garantir a própria perpetuação do sistema, através dos diversos meios de controle social; e, finalmente, dar origem aos sistemas de tipificações e relevâncias individuais, colocando os problemas particulares no contexto dos problemas do grupo (SCHUTZ, 1979, p. 119-120).

Fica clara, portanto, a importância dos sistemas de relevância e tipificação nos postulados teóricos de Alfred Schutz. É através do contato intersubjetivo que se dá a ligação dos indivíduos com a realidade já construída e, portanto, linguagem e comunicação estão no cerne da sociabilidade. A atividade dos meios de comunicação é um dos elementos de ligação entre os indivíduos e suas experiências, onde se manifestam e/ou criam-se as tipificações e as relevâncias, já que eles influem decisivamente nos "processos pelos quais qualquer corpo de conhecimento chega a ser socialmente estabelecido como realidade" (BERGER e LUCKMANN, 1991, p. 13-14).

\section{A fENOMENOLOGIA SOCIAL E A COMUNiCAÇÃo}

Vimos que a relevância atua como um "dispositivo pelo qual se elege o que é importante para um grupo ou sistema social" (CORREIA, 2005, p. 126-127) e que a partilha de significados entre indivíduos é determinante nas suas ações. A atuação dos meios de comunicação é importante em ambos os aspectos, ou seja, na definição dos assuntos relevantes para a agenda pública e também para a consolidação ou para o questionamento dos significados partilhados.

Nesse sentido, cabe perguntar o que transforma fatos em notícias relevantes, ou de onde surge o sistema de relevâncias dado nos meios de comunicação. Correia (2005) apoia-se no conceito de valor-notícia' para afir-

1 Conceito oriundo das teorias de news making, centradas na questão da produção das 
mar que os elementos que tornam um fato ou uma informação dignos de ocuparem o espaço midiático "[...] refletem a intersecção entre o sistema de relevâncias vigente na redação, no grupo profissional e no mundo da vida em que estão inseridos" (2005, p. 128), além das limitações impostas pela organização do trabalho jornalístico, as restrições orçamentárias e a interação com a audiência. Assim, entendemos que a relação entre a mídia e a relevância não se dá simplesmente na escolha das notícias, mas na forma como sua redação ajuda a determinar ou reforçar o que é importante.

Nesse processo, a mídia age no terreno das tipificações, reforçando ou questionando as generalizações construídas através da experiência e que definem a apreciação que fazemos de determinadas partes do mundo da vida. A informação midiatizada amplia a potencialidade daquilo que nos é possível experimentar, mas, em um primeiro momento, todas essas informações são submetidas ao que já se sabe, ou seja, a um conhecimento prévio que já nos é familiar:

As tipificações são a forma que a atitude natural do mundo da vida tem de lidar com a erupção generalizada da novidade. São o modo de estabelecer regularidades num mundo ameaçado pela contingência. São a forma de assegurar que é possível lidar com o mundo como até aí. Obviamente que o ator, no mundo social, parece menosprezar tal contingência, tal novidade, tal estranheza. Age [...] como se o mundo lhe surgisse como uma evidência tida por adquirida. Na realidade, o mundo da vida é paradoxal. Como Schutz adivinha, um mundo pode ser instável, marcado pela aceleração das diferenças, pela erupção de acontecimentos permanentes. Porém, aos olhos dos agentes que o integram, as tipificações permitem lidar com essas mudanças de um modo que lhes parece evidente. Nesse sentido, até acontecimentos como a morte são tipificados de um modo que lhes permite serem absorvidos pela visão relativamente natural do mundo que faz parte da vida cotidiana (CORREIA, 2005, p. 131).

Esse processo revela um aspecto bastante interessante da produção de notícias, já que, de forma geral, como verificou Bourdieu (1997), a mídia trata cotidianamente do extracotidiano e, para que isso aconteça, há uma parcela de construção, de produção de sentido, que relaciona o que é considerado extraordinário com a ordem natural do mundo da vida, tal como considerada nas

notícias e trabalhadas por diversos autores. Correia cita Nelson Traquina como referência. 
diferentes condições de produção jornalística. Assim, a noção de objetividade fica abalada, pois a realidade não pode ser separada da forma como é interpretada pelo campo jornalístico, tomando emprestada a concepção bourdiana.

As tipificações envolvem também questões práticas de ordem espaçotemporal, como a periodicidade do veículo e os limites de espaço (toques, minutos), de forma que a informação midiatizada está sujeita a todo um quadro de tipos e relevâncias tidos como aceitáveis socialmente, seja na experiência individual dos jornalistas, seja nos diversos fatores que influenciam o processo de produção. É produzida uma orientação discursiva que cerceia a descrição da realidade, adequando-a ao veículo e à comunidade onde ele está inserido. Explica Correia (2005):

Os jornalistas são elementos essenciais na construção de imagens que só tem sentido insertas numa história exemplar em que colaboram todas as formas institucionais de narradores e o próprio público. A estrutura subjacente acaba por percorrer formas diversas de relato de modo a proporcionar a adesão ou a repulsa. As imagens funcionam como os arquétipos que se usam para criar esse relato, inserindo-o de modo articulado no conjunto de narrativas dominantes numa dada cultura. De acordo com esta estratégia, a sociedade cria imagens negativas e positivas mas inscreve-as na concepção relativamente natural da comunidade. O risco é o de que, deste modo, se desencadeie uma operação coletiva de naturalização do que é cultural que acentue a vocação alegadamente universal dos valores e visões transmitidos, omitindo os elementos conflituais e contraditórios (CORREIA, 2005, p. 134).

Desta forma, os jornais e jornalistas reforçam as relevâncias e tipificações tidas como dominantes; ocorre uma correspondência entre as rotinas profissionais e a atitude natural. Porém, muito do que é dado como a priori na mídia pode ser questionado, tensionado, posto em dúvida. Chegamos, assim, a um dos pontos mais interessantes da atividade jornalística: a objetividade.

Como o pesquisador, o jornalista faz parte do mundo que observa e interpreta. Os próprios eventos que ele noticia já são, eles mesmos, construções da realidade. $O$ desafio é evitar que a proximidade com o senso comum se transforme em conformismo. A esta dificuldade metodológica, a abordagem fenomenológica schutziana responde com a afirmação do ponto de vista subjetivo, ou seja, com a incorporação do jornalista como observador, mas também agente do processo social. Esta situação propicia ao profissio- 
CONTRIBUIÇÕES DA SOCIOLOGIA FENOMENOLÓGICA

DE ALFRED SCHUTZ PARA A COMUNICAÇÃO

nal a possibilidade de conhecer outros âmbitos de significado:

Ao ganhar consciência do seu estatuto de observador e participante, o resultado poderá ser a possibilidade de o jornalista se tornar ainda mais observador, desenvolvendo a confiança a suspeita (num sentido positivo), mais atento à situação complicada que resulta da sua posição peculiar (CORREIA, 2005, p. 139).

A interação entre províncias de significado não se dá sem conflitos, desentendimentos ou falhas de comunicação, tanto no plano individual quanto no coletivo. As contradições de uma província de significado só se tornam aparentes no contato com o estrangeiro, onde a posição natural perante o mundo é questionada e provocada à reflexão. As relações políticas, por exemplo, pressupõem o eminente contato entre diferentes, de forma que o dissenso e o desentendimento sempre estarão presentes. Nesse caso, a forma como um grupo se vê (suas autotipificações) entram em choque com as heterotipificações de outrem, de forma a surgir antagonismo ou confronto. Esse encontro também pode gerar reflexão, relativização e entendimento. Isso se manifesta também no espaço midiático: "as situações comunicativas da vida cotidiana não são idênticas às do espaço público e a interação entre elas é um elemento essencial de sobressalto e contingência, de introdução da estranheza e de questionamento da identidade" (CORREIA, 2005, p. 147).

\section{CONSIDERAÇÕES}

Dada a impossibilidade de reconstituir a experiência através da reflexão, como assinalou Schutz, cabe-nos, como pesquisadores da área da Comunicação, buscar desenhar o melhor mapa possível para o território de nosso objeto, com as ferramentas metodológicas escolhidas. Nesse sentido, a Sociologia Fenomenológica de Alfred Schutz é encarada como uma tentativa radical de ir além das mais simples pressuposições básicas, questionando a própria ideia de conhecimento, dirigindo-se às próprias coisas, aos fenômenos e às formas como eles nos aparecem (CORREIA, 2005):

A concepção fenomenológica implica, assim, a existência de um determinado método que se traduz na adoção de uma certa atitude. Pretende- se que o fenomenólogo enfrente o seu objeto de estudo com uma particular disposição da consciência, com uma atitude característica e com um modo particular de questionar sua relação com o objeto (p. 43). 
Mesmo situando o pesquisador como elemento do real e utilizando a salvaguarda do ponto de vista subjetivo que a sociologia fenomenológica permite, é importante ressaltar que, como método, ela não está entrincheirada no individualismo ou no conformismo; ao contrário, pretende valorizar o conhecimento cotidiano expresso nos meios de comunicação como uma rica manifestação da construção de sentido em sua mais profunda polissemia, na fortuna dos estranhamentos e da impossibilidade que faz do fenômeno comunicativo um dos mais ricos para a pesquisa social.

\section{REFERÊNCIAS}

BERGER, Peter; LUCKMANN, Thomas. A construção social da realidade. Petrópolis: Vozes, 1991.

BOURDIEU, Pierre. Sobre a televisão. Rio de Janeiro: Zahar, 1997.

CORREIA, João Carlos. A teoria da comunicação de Alfred Schutz. Lisboa: Horizonte, 2005. MAFFESOLI, Michel. O conhecimento comum: Introdução à sociologia compreensiva. Porto Alegre: Sulina, 2007.

SCHUTZ, Alfred. Fenomenologia e relações sociais. Rio de Janeiro: Zahar, 1979. WAGNER, Helmut. "A abordagem fenomenológica da sociologia". In: SCHUTZ, Alfred. Fenomenologia e relações sociais. Rio de Janeiro: Zahar, 1979.

\section{Camila Garcia Kieling}

Doutoranda no Programa de Pós-Graduação em Comunicação Social da Pontifícia Universidade Católica do Rio Grande do Sul (Porto Alegre, RS, Brasil). Mestre em Comunicação pela mesma instituição. 